\title{
Early impact of school closure and social distancing for COVID-19 on the number of inpatients with childhood non-COVID-19 acute infections in Japan
}

\author{
Kenji Kishimoto $^{1} \cdot$ Seiko Bun ${ }^{1,2} \cdot$ Jung-ho Shin $^{1} \cdot$ Daisuke Takada $^{1} \cdot$ Tetsuji Morishita $^{1} \cdot$ Susumu Kunisawa $^{1}$. \\ Yuichi Imanaka ${ }^{1}$ iD
}

Received: 11 November 2020 /Revised: 5 March 2021 / Accepted: 21 March 2021 / Published online: 31 March 2021

(C) The Author(s), under exclusive licence to Springer-Verlag GmbH Germany, part of Springer Nature 2021

\begin{abstract}
Many countries have implemented school closures as part of social distancing measures intended to control the spread of coronavirus disease 2019 (COVID-19). The aim of this study was to assess the early impact of nationwide school closure (March-May 2020) and social distancing for COVID-19 on the number of inpatients with major childhood infectious diseases in Japan. Using data from the Diagnosis Procedure Combination system in Japan, we identified patients aged 15 years or younger with admissions for a diagnosis of upper respiratory tract infection (URTI), lower respiratory tract infection (LRTI), influenza, gastrointestinal infection (GII), appendicitis, urinary tract infection (UTI), or skin and soft tissue infection (SSTI) between July 2018 and June 2020. Changes in the trend of the weekly number of inpatients between the two periods were assessed using interrupted time-series analysis. A total of 75,053 patients in 210 hospitals were included. The overall weekly number of inpatients was decreased by $52.5 \%, 77.4 \%$, and by $83.4 \%$ in the last week of March, April, and May 2020, respectively, when compared on a year-on-year basis. The estimated impact was a reduction of 581 (standard error 42.9) inpatients per week in the post-school-closure period $(p<0.001)$. The main part of the reduction was for pre-school children. Remarkable decreases in the number of inpatients with URI, LRTI, and GII were observed, while there were relatively mild changes in the other groups.

Conclusion: We confirmed a marked reduction in the number of inpatients with childhood non-COVID-19 acute infections in the post-school-closure period.
\end{abstract}

What is Known:

- Most countries have implemented social distancing measures to limit the spread of the novel coronavirus disease 2019 (COVID-19).

- A large decrease in pediatric emergency visits has been reported from several countries after the social distancing.

What is New:

- Based on administrative claims data, a marked reduction in the number of inpatients for childhood non-COVID-19 acute infections was found in the post-school-closure period in Japan.

- The magnitude of the reduction was different between the disease groups.

Keywords COVID-19 - School closure $\cdot$ Social distancing $\cdot$ Acute infection

Communicated by Nicole Ritz

Yuichi Imanaka

imanaka-y@umin.net

Kenji Kishimoto

ken@yacht.ocn.ne.jp

Seiko Bun

bun.seiko.58w@st.kyoto-u.ac.jp

Jung-ho Shin

shin.jungho.76v@st.kyoto-u.ac.jp

Daisuke Takada

daisuke.gaotian@gmail.com
Tetsuji Morishita

morishita.tetsuji.42z@st.kyoto-u.ac.jp

Susumu Kunisawa

kunisawa.susumu.2v@kyoto-u.ac.jp

1 Department of Healthcare Economics and Quality Management, Graduate School of Medicine, Kyoto University, Yoshida Konoe-cho, Sakyo-ku, Kyoto 606-8501, Japan

2 Department of Pharmacy, National Center for Child Health and Development Hospital, Tokyo, Japan 


\section{Introduction}

The current coronavirus disease 2019 (COVID-19) pandemic $[1,2]$ has led to over $2,440,000$ deaths worldwide [3] and has resulted in substantial changes in the practice of health care. Most countries have implemented social distancing measures to limit the spread of the novel coronavirus SARS-CoV-2, which is responsible for COVID-19 [2, 4]. The impact of the COVID-19 pandemic on health care for children has been described in areas such as emergency departments $[5,6]$ and chronic disease care facilities [7, 8]. The number of children with acute infection, the most common presentation of children to hospitals, also appears to be affected by the COVID19 pandemic. One recent study showed a large decrease in pediatric emergency visits and admissions following emergency visits for viral infections after the school closure and national lockdown [9]. Another study has reported an unprecedented decline in hospital admissions for children younger than 3 years with respiratory infections after social distancing [10]. However, there is little information on the overall change in the number of hospitalized children with acute infections caused by school closure and social distancing.

Many countries have implemented school closures nationwide as part of social distancing measures, although the effect of school closures on the epidemic has not been fully investigated [11-13]. In Japan, the first COVID-19 case was reported on 16 January 2020 . As the severity of the outbreak became evident, the Japanese government called for the closure of all elementary schools (for children aged 6-12 years), junior high schools (for ages 12-15 years), and high schools (for ages 1518 years) on 27 February 2020. Nursery schools were excluded from the nationwide closure request. A state of emergency was then declared, initially for seven prefectures on 7 April, later nationwide on 16 April 2020. The state of emergency was lifted nationwide on 25 May 2020, and most schools had reopened by the first week of June 2020 [14]. The aim of this study was to assess the early impact of school closure and social distancing for COVID-19 on the number of inpatients with major childhood infectious diseases in Japan using administrative claims data.

\section{Material and methods}

\section{Data source}

Data were obtained from the database of the Quality Indicator/ Improvement Project (QIP), an ongoing project in Japan intended to monitor and improve clinical performance in acute care hospitals through the analysis of administrative claims data [15]. Over 500 hospitals across Japan, including both public and private hospitals, have participated in the QIP since its inception in 1995. The QIP database contains Diagnosis
Procedure Combination (DPC) administrative claims data from the participating hospitals. The DPC data includes information on hospital codes, patient demographics, admission and discharge dates, admission routes, outcomes, primary and secondary diagnoses based on International Classification of Diseases 10th revision (ICD-10) codes, comorbidities, complications, and claims for medical services [16].

\section{Study population and disease definitions}

Data from 257 hospitals in the QIP that had submitted DPC data on both inpatients and outpatients for the study period of July 2018 through June 2020 were used to select the study population. (Only data submitted prior to 26 August 2020 were considered.) Seven groups of infectious diseases were distinguished: upper respiratory tract infection (URTI), lower respiratory tract infection (LRTI), influenza, gastrointestinal infection (GII), appendicitis, urinary tract infection (UTI), and skin and soft tissue infection (SSTI). All patients aged 15 years or younger with admissions for a primary diagnosis and the most medical resource-intensive diagnosis within the seven disease groups between July 2018 and June 2020 were included in the study. Patients with a diagnosis of coronavirus infection or COVID-19 (defined by ICD-10 codes B34.2 or U07.1) were excluded. Two age groups were defined: preschool children (aged 0-5 years) and school-age children (aged 6-15 years). URTI was defined by ICD-10 codes J00.x through J06.x. LRTI was defined by ICD-10 codes J12.x through J40.x. Influenza was defined by ICD-10 codes J09.x through J11.x. GII was defined by ICD-10 codes A00.x through A09.x. Appendicitis was defined by ICD-10 codes K35.x through K37.x. UTI was defined by ICD-10 codes N10.x, N13.6, N15.1, N30.x, N34.x, and N39.0. SSTI was defined by ICD-10 codes L00.x through L08.x.

\section{Statistical analysis}

The primary outcome of interest was the weekly number of inpatients. We used the date of discharge rather than the date of admission for comparing the number of weekly inpatients, since the DPC data were generated after discharge. The observed weekly number of inpatients between July 2018 and June 2019 was compared to that between July 2019 and June 2020, as a year-on-year comparison. The secondary outcome was the change in the trend of the weekly number of inpatients before and after the school closure in March 2020. Two periods were considered in the analysis: the pre-schoolclosure period (1 July 2018, through 29 February 2020) and the post-school-closure period (1 March 2020 through 30 June 2020). Changes in the trend of the weekly number of inpatients were analyzed by segmented regressions and an interrupted time-series design to estimate the effects of the school closure [17]. The seasonality of hospital admissions 
for pediatric infectious disease was taken into account by including harmonic terms with a 52-week period. The intervention effect (decrease in the number of inpatients) was estimated by comparing estimates in the post-school-closure period to expected estimates from a Gaussian regression model. The validity of the regression model was assessed by visual inspection. Overall analysis and stratified analyses by age group and disease group were performed. A $p$ value of less than 0.05 was considered statistically significant; all tests were twotailed. All analyses were conducted using $\mathrm{R}$ version 4.0.2 (The R Development Core Team, Vienna, Austria).

\section{Ethical considerations}

This study was approved by the Ethics Committee, Graduate School of Medicine, Kyoto University (approval number: R0135) and conducted in accordance with the Ethical Guidelines for Medical and Health Research Involving Human Subjects of the Ministry of Health, Labour and Welfare, Japan.

\section{Results}

In all, 75,101 patients in 210 hospitals who met the inclusion criteria during the study period were identified from the database. Forty-eight patients with coronavirus infection or COVID-19 were excluded from the group. Thus, 75,053 patients in 210 hospitals in the seven disease groups were included in the analyses. Patient characteristics are summarized in Table 1. LRTI was the most common disease group (51.9\%). The second most frequent group was GII (15.4\%), followed by URTI (13.8\%), influenza (5.8\%), UTI (5.1\%), appendicitis (4.7\%), and SSTI (3.3\%). Table 2 describes the characteristics of patients in the pre-school-closure period and the post-school-closure period.

\section{Change in the overall number of inpatients}

Figure 1 shows a year-on-year comparison of the observed weekly number of inpatients during the study period. We found a marked reduction in the number of inpatients in the post-school-closure period (Fig. 1a). The reduction in the number of inpatients had already become substantial by the end of March 2020. The overall weekly number of inpatients was 638 in the last week of February 2020, 375 in the last week of March 2020, 276 in the last week of April 2020, and 166 in the last week of May 2020. When compared on a yearon-year basis, the overall weekly number of inpatients was decreased by $9.1 \%, 52.5 \%, 77.4 \%$, and by $83.4 \%$ in the last week of February, March, April, and May 2020, respectively. Figure 2 illustrates the time trend of weekly number of inpatients and the results of the interrupted time-series analysis.
The estimated impact from the interrupted time series analysis was a reduction of 581 (standard error 42.9) inpatients per week between the two periods $(p<0.001)$ (Fig. 2a).

\section{Stratified analysis by age group and disease group}

A major reduction in the number of inpatients was observed in the post-school-closure period for both pre-school children and school-age children (Fig. 1b, c). When compared on a year-on-year basis, the weekly number of pre-school and school-age inpatients was decreased by $56.4 \%$ and by $38.4 \%$ in the last week of March 2020, respectively. As the baseline numbers of inpatients was higher for pre-school children than for school-age children, pre-school children accounted for the main part of the reduction in the number of inpatients. The interrupted time-series analysis confirmed a prominent decrease in the number of inpatients in both age groups (Fig. $2 b, c)$. We found that the magnitude of the decrease in the number of inpatients after the school closure was different between the disease groups (Fig. 1d-j). Remarkable decreases in the number of inpatients with URI, LRTI, and GII were observed in the post-school-closure period. By contrast, there were relatively mild changes in the influenza, appendicitis, UTI, and SSTI groups. The main part of the reduction in the number of inpatients was in the LRTI and GII groups. The interrupted time series analysis showed a pronounced decrease in the number of inpatients in the URTI, LRTI, and GII groups (Fig. 2d-j).

\section{Discussion}

We found that the number of children hospitalized as inpatients for non-COVID-19 acute infections decreased markedly in the post-school-closure period in Japan. This was true for both pre-school children and school-age children. We also found the different impact on the number of inpatients between the disease groups. These results suggest the potential impact of school closure and social distancing for COVID-19 on the number of inpatients with childhood infectious diseases. We considered the nationwide school closure rather than the government's declaration of a state of emergency as the primary cause of the reduction, as the reduction had already been observed in March 2020, prior to the emergency declaration in April 2020.

Our results showed that the decrease in the number of inpatients after the school closure was observed not only in school-age children but also in pre-school children, which is consistent with previous reports on the effect of the COVID19 pandemic on pediatric acute infection $[9,10]$. Indeed, the absolute decrease in the number of inpatients was much greater in pre-school children. Moreover, the reduction in the number of inpatients was more prominent in transmissible 
Table 1 Characteristics of patients by overall inpatients and disease groups

\begin{tabular}{|c|c|c|c|c|c|c|c|c|}
\hline & $\begin{array}{l}\text { Overall } \\
75,053\end{array}$ & $\begin{array}{l}\text { URTI } \\
10,382\end{array}$ & $\begin{array}{l}\text { LRTI } \\
38,978\end{array}$ & $\begin{array}{l}\text { Influenza } \\
4,350\end{array}$ & $\begin{array}{l}\text { GII } \\
11,586\end{array}$ & $\begin{array}{l}\text { Appendicitis } \\
3,492\end{array}$ & $\begin{array}{l}\text { UTI } \\
3,814\end{array}$ & $\begin{array}{l}\text { SSTI } \\
2,451\end{array}$ \\
\hline \multicolumn{9}{|l|}{ Number of inpatients } \\
\hline Median age (years (IQR)) & $1(0-4)$ & $1(0-4)$ & $1(0-2)$ & $4(1-7)$ & $3(1-7)$ & $11(9-13)$ & $0(0-2)$ & $3(1-7)$ \\
\hline \multicolumn{9}{|l|}{ Age group (n (\%)) } \\
\hline$<1$ year & $20,939(27.9)$ & 3187 (30.7) & $12,774(32.8)$ & $633(14.6)$ & $1633(14.1)$ & $0(0.0)$ & $2348(61.6)$ & 364 (14.9) \\
\hline $1-5$ years & $38,831(51.7)$ & $5571(53.7)$ & $22,704(58.2)$ & $2110(48.5)$ & $6177(53.3)$ & $125(3.6)$ & $859(22.5)$ & $1285(52.4)$ \\
\hline $6-10$ years & $9611(12.8)$ & $1173(11.3)$ & $2459(6.3)$ & $1240(28.5)$ & $2553(22.0)$ & $1264(36.2)$ & $360(9.4)$ & $562(22.9)$ \\
\hline $11-15$ years & $5672(7.6)$ & $451(4.3)$ & $1041(2.7)$ & $367(8.4)$ & $1223(10.6)$ & $2103(60.2)$ & $247(6.5)$ & $240(9.8)$ \\
\hline \multicolumn{9}{|l|}{$\operatorname{Sex}(n(\%))$} \\
\hline Female & $33,879(45.1)$ & 4567 (44.0) & $18,056(46.3)$ & $1775(40.8)$ & $5271(45.5)$ & $1367(39.1)$ & $1771(46.4)$ & $1072(43.7)$ \\
\hline Male & $41,174(54.9)$ & $5815(56.0)$ & $20,922(53.7)$ & $2575(59.2)$ & $6315(54.5)$ & $2125(60.9)$ & $2043(53.6)$ & $1379(56.3)$ \\
\hline Median hospital stay (days (IQR)) & $5(4-6)$ & $4(3-5)$ & $5(4-6)$ & $4(3-5)$ & $4(3-5)$ & $5(4-7)$ & $7(5-9)$ & $6(5-8)$ \\
\hline
\end{tabular}

Abbreviations: GII, gastrointestinal infection; IQR, interquartile range; LRTI, lower respiratory tract infection; SSTI, skin and soft tissue infection; URTI, upper respiratory infection; UTI urinary tract infection

infectious diseases such as URI, LRTI, and GII. Regarding admissions for influenza, the relatively mild change in the post-school-closure period may be due to its coinciding with the end of the influenza season. While these findings could be used to support a hypothesis that the decreased transmission of pathogens among younger children due to social distancing following school closure is responsible for the remarkable decrease in the number of inpatients observed in this study, another possible explanation is hospital avoidance during the COVID-19 pandemic [18, 19]. This would not be without precedent as previous studies have reported healthcare avoidance in epidemics or outbreaks of emerging infectious diseases [20, 21]. Further studies using community-based data that include primary care settings are needed to estimate the
Table 2 Characteristics of patients in the pre-school-closure period and the post-schoolclosure period

\begin{tabular}{|c|c|c|}
\hline Characteristic & $\begin{array}{l}\text { Pre-school-closure period } \\
\text { (1 July 2018-29 February 2020) }\end{array}$ & $\begin{array}{l}\text { Post-school-closure period } \\
\text { (1 March 2020-30 June 2020) }\end{array}$ \\
\hline Overall $(n(\%))$ & $69,920(100.0)$ & $5133(100.0)$ \\
\hline \multicolumn{3}{|c|}{ Disease group $(n(\%))$} \\
\hline URTI & 9485 (13.6) & $897(17.5)$ \\
\hline LRTI & $36,976(52.9)$ & $2002(39.0)$ \\
\hline Influenza & $4255(6.1)$ & $95(1.9)$ \\
\hline GII & $10,867(15.5)$ & $719(14.0$ \\
\hline Appendicitis & $2952(4.2)$ & $540(10.5)$ \\
\hline UTI & 3207 (4.6) & $607(11.8)$ \\
\hline SSTI & $2178(3.1)$ & $273(5.3)$ \\
\hline \multicolumn{3}{|c|}{ Age group $(n(\%))$} \\
\hline$<1$ year & $19,720(28.2)$ & $1219(23.7)$ \\
\hline $1-5$ years & $36,374(52.0)$ & $2457(47.9)$ \\
\hline $6-10$ years & $8810(12.6)$ & $801(15.6)$ \\
\hline $11-15$ years & $5016(7.2)$ & $656(12.8)$ \\
\hline \multicolumn{3}{|l|}{$\operatorname{Sex}(n(\%))$} \\
\hline Female & $31,535(45.1)$ & $2344(45.7)$ \\
\hline Male & $38,385(54.9)$ & $2789(54.3)$ \\
\hline \multicolumn{3}{|c|}{ Median hospital stay (days (IQR)) } \\
\hline URTI & $4(3-5)$ & $4(3-5)$ \\
\hline LRTI & $5(4-6)$ & $5(4-6)$ \\
\hline Influenza & $4(3-5)$ & $4(3-5)$ \\
\hline GII & $4(3-5)$ & $4(3-5)$ \\
\hline Appendicitis & $5(4-7)$ & $5(4-6)$ \\
\hline UTI & $7(5-9)$ & $7(5-9)$ \\
\hline SSTI & $6(5-8)$ & $6(5-8)$ \\
\hline
\end{tabular}

Abbreviations: GII, gastrointestinal infection; IQR, interquartile range; LRTI, lower respiratory tract infection; SSTI, skin and soft tissue infection; URTI, upper respiratory infection; UTI, urinary tract infection 

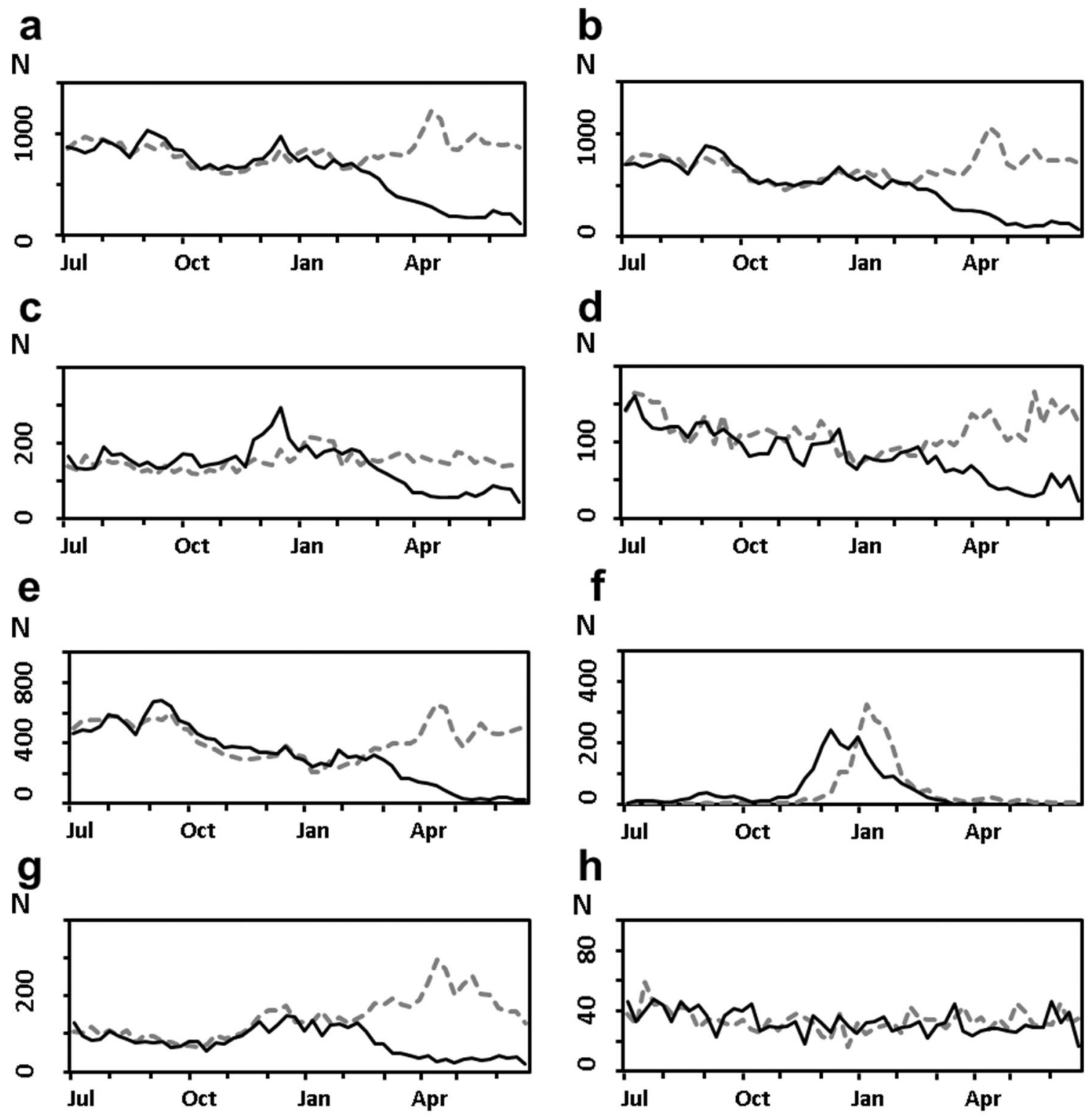

h
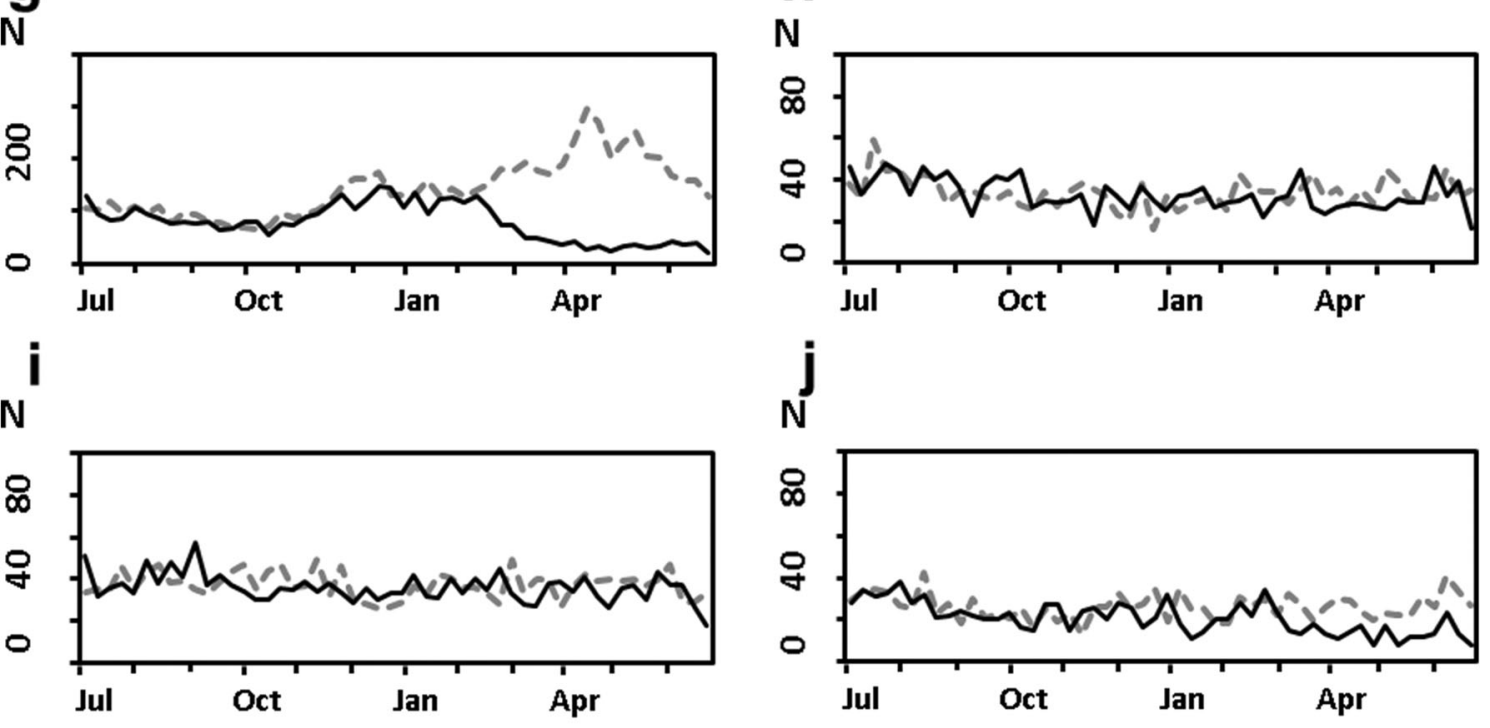

\section{- July 2018 - June 2019 - - July 2019 - June 2020}

Fig. 1 A year-on-year comparison of the observed weekly number of inpatients during the study period. Solid lines indicate the trend between July 2018 and June 2019, and dashed lines indicate the trend between July 2019 and June 2020. a Overall population; b pre-school children (aged 0-5 years); c school-age children (aged 6-15 years); $\mathbf{d}$ patients with
URTI; e patients with LRTI; $\mathbf{f}$ patients with influenza; $\mathbf{g}$ patients with GII; h patients with appendicitis; i patients with UTI; j patients with SSTI. Abbreviations: GII, gastrointestinal infection; LRTI, lower respiratory tract infection; SSTI, skin and soft tissue infection; URTI, upper respiratory infection; UTI urinary tract infection 

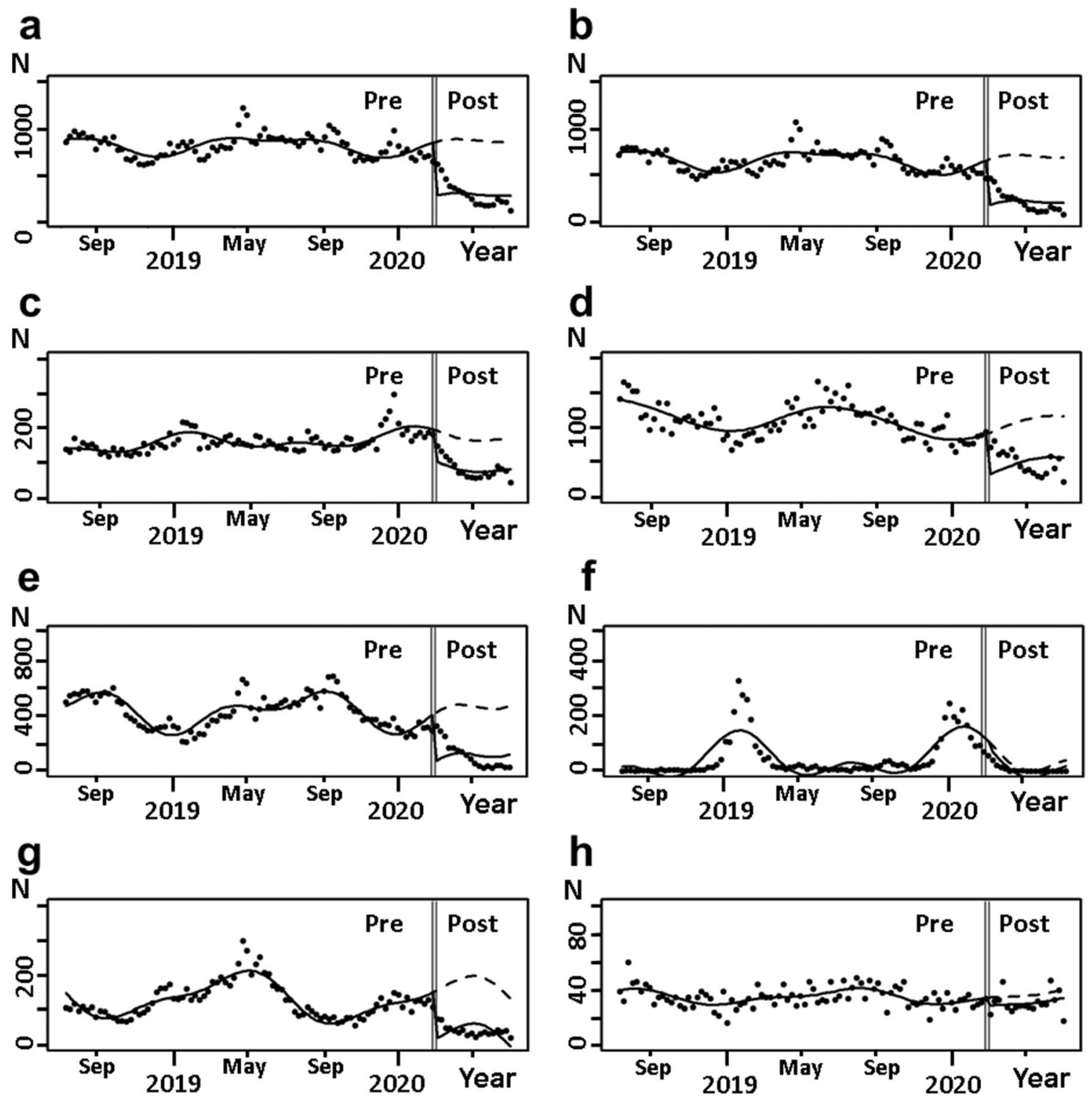

$\mathrm{h}$
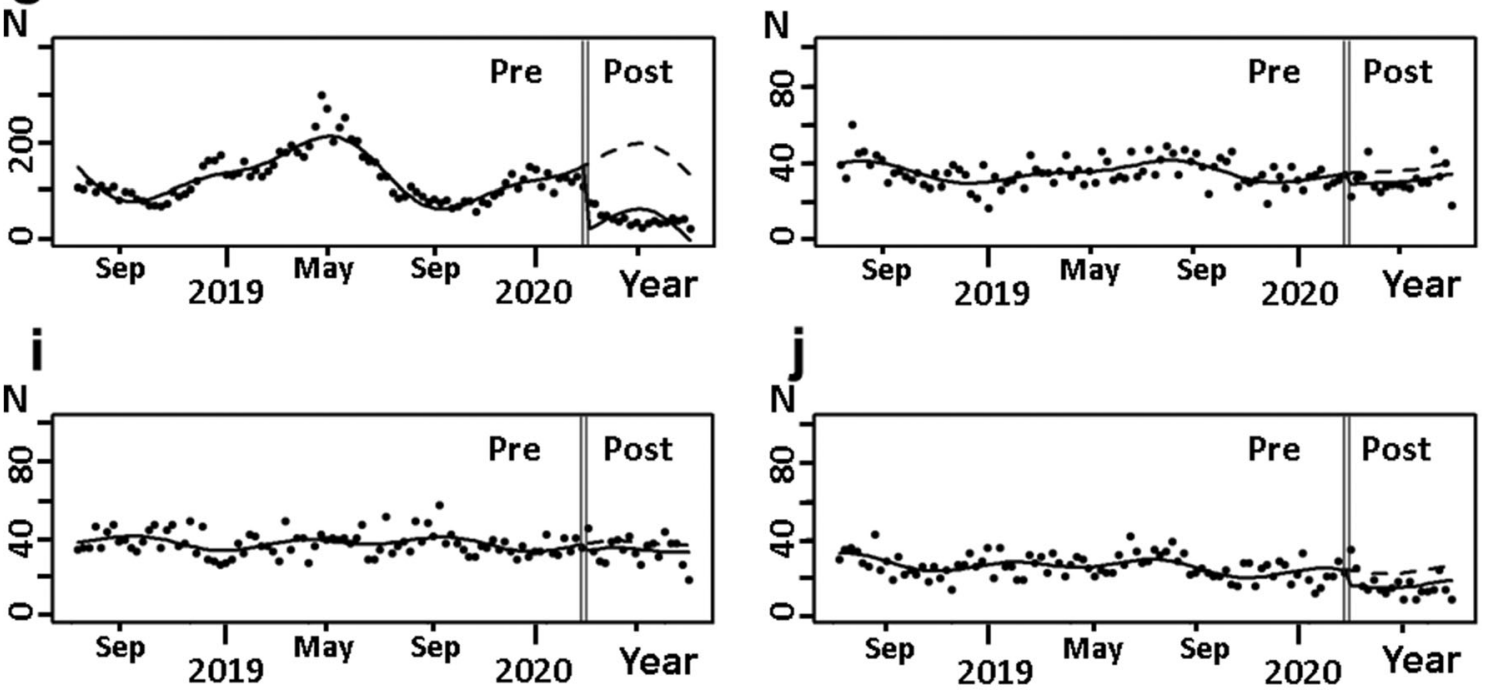

Observed weekly number of inpatients

Fig. 2 Time trend in the number of inpatients and the results of the interrupted time-series analysis. Black dots indicate the observed weekly number of inpatients, solid lines indicate observed trend following school closure for COVID-19, and dashed lines indicate predicted trend. Vertical double bars indicate the initiation of nationwide school closure in March 2020. The estimated coefficient $(\beta)$ for the change in the number of inpatients per week, standard error (SE) for $\beta$ and $p$ value are as follows: a overall population $(\beta=$ $-581.1, \mathrm{SE} 42.9, p<0.001)$; b pre-school children (aged $0-5$ years) $(\beta=$ -491.9 , SE 38.4, $p<0.001)$; c school-age children (aged $6-15$ years) $(\beta=$

-89.3 , SE 9.0, $p<0.001)$; d patients with URTI $(\beta=-59.2$, SE 7.0, $p<$ $0.001)$; e patients with LRTI $(\beta=-347.5$, SE $28.8, p<0.001)$; f patients with influenza $(\beta=-21.8$, SE $16.5, p=0.19)$; g patients with GII $(\beta=-135.7$, SE $9.2, p<0.001)$; h patients with appendicitis $(\beta=-5.7$, SE $2.5, p=0.027)$; patients with UTI $(\beta=-3.7$, SE $2.4, p=0.13)$; j patients with SSTI $(\beta=-7.5$, SE 2.3, $p=0.001)$. Abbreviations: COVID-19, coronavirus disease 2019; GII, gastrointestinal infection; LRTI, lower respiratory tract infection; SSTI, skin and soft tissue infection; URTI, upper respiratory infection; UTI urinary tract infection 
impact of hospital avoidance. As UTI has been regarded as a non-transmissible disease in past studies of childhood infection [22, 23], the fact that the number of inpatients for UTI did not show an obvious change in the post-school-closure period may suggest that the impact of hospital avoidance was not particularly high.

Current evidence on the effect of school closures and social distancing has been derived almost entirely from studies of influenza outbreaks $[24,25]$. The effectiveness of social distancing among children in other outbreaks, including COVID19, remains unclear. Dealing with the COVID-19 pandemic clearly requires massive healthcare resources $[26,27]$. A reduction in hospital admissions for childhood infections may save healthcare resources that could then be utilized for COVID-19 care. As the estimated costs and negative impacts of school closure are significant [28-30], our results can be useful for policy making in the ongoing COVID-19 pandemic or in future outbreaks.

This study has several limitations. The study population, which was restricted to a certain segment of hospitals in the QIP, is perhaps the primary limitation. The movement of patients from the enrolled hospitals to other facilities during the COVID-19 pandemic may have caused an overestimation of the reduction in the number of inpatients in the post-schoolclosure period. However, a relatively consistent trend in the number of inpatients in the influenza and UTI groups during the study period suggests that there was no large-scale movement of patients from the enrolled hospitals. A lack of information on disease severity is another limitation of the study. Changes in disease severity in the enrolled patients between the two periods were not assessed, as the DPC data are not sufficient to evaluate the severity of a childhood infectious disease. The third limitation is our use of the date of discharge rather than the date of admission for comparing the number of weekly inpatients. This may cause an underestimation of the impact of school closure and social distancing in the postschool-closure period, especially in the early weeks. Considering the relatively short hospital stay of the patients, this effect seems to be limited. The fourth limitation is that the study included only the Japanese population. It should be noted that no mandatory social distancing or so-called lockdowns were imposed by the Japanese government. As there have been considerable regional differences in the spread of COVID-19 and in the various epidemic-control measures taken globally, it is difficult to predict whether the present findings for Japan are applicable elsewhere. Despite these limitations, our study provides novel information on the impact of the COVID-19 pandemic on health care for children.

In summary, we confirmed a marked reduction in the number of school-age and pre-school inpatients for non-COVID-19 acute infections in the post-school-closure period. We showed that the main part of the reduction was for pre-school children, particularly in the LRTI and GII disease groups.
Abbreviations COVID-19, coronavirus disease 2019; DPC, Diagnosis Procedure Combination; GII, gastrointestinal infection; ICD-10, International Classification of Diseases 10th revision; LRTI, lower respiratory tract infection; QIP, Quality Indicator/Improvement Project; SSTI, skin and soft tissue infection; URTI, upper respiratory infection; UTI, urinary tract infection

Acknowledgements We gratefully acknowledge the participating hospitals in the QIP and their staffs. We also acknowledge the colleagues in the Department of Healthcare Economics and Quality Management, Graduate School of Medicine, Kyoto University, Japan.

Availability of data and material The datasets analyzed during the current study are available from the corresponding author on reasonable request.

Code availability Not applicable.

Authors' contributions Dr. Kishimoto and Dr. Bun conceptualized and designed the study, drafted the initial manuscript, and reviewed and revised the manuscript. Dr. Shin, Takada, and Morishita designed the data collection instruments, collected data, carried out the initial analyses, and reviewed and revised the manuscript. Dr. Kunisawa designed the data collection instruments, collected data, and reviewed and revised the manuscript. Dr. Imanaka conceptualized and designed the study, coordinated and supervised data collection, and critically reviewed the manuscript for important intellectual content. All authors approved the final manuscript as submitted and agree to be accountable for all aspects of the work.

Funding This study was supported by the Japan Society for the Promotion of Science (JSPS KAKENHI Grant Number JP19H01075 to Y.I.) and GAP Fund Program of Kyoto University.

\section{Declarations}

Ethics approval This study was approved by the Ethics Committee, Graduate School of Medicine, Kyoto University (approval number: R0135).

Consent to participate Not applicable.

Consent for publication Not applicable.

Conflict of interest The authors declare no conflict of interest.

\section{References}

1. Xie Y, Wang Z, Liao H, Marley G, Wu D, Tang W (2020) Epidemiologic, clinical, and laboratory findings of the COVID-19 in the current pandemic: systematic review and meta-analysis. BMC Infect Dis. 20:640

2. Patel U, Malik P, Mehta D, Shah D, Kelkar R, Pinto C et al (2020) Early epidemiological indicators, outcomes, and interventions of COVID-19 pandemic: a systematic review. J Glob Health. 10: 020506

3. COVID-19 Map - Johns Hopkins Coronavirus Resource Center. https://coronavirus.jhu.edu/map.html. Accessed 19 February 19, 2021

4. Coronaviridae Study Group of the International Committee on Taxonomy of Viruses (2020) The species severe acute respiratory syndrome-related coronavirus: classifying 2019-nCoV and naming it SARS-CoV-2. Nat Microbiol. 5:536-544

5. Hartnett KP, Kite-Powell A, DeVies J, Coletta MA, Boehmer TK, Adjemian $J$ et al (2020) Impact of the COVID-19 pandemic on 
emergency department visits - United States, January 1, 2019-May 30, 2020. MMWR Morb Mortal Wkly Rep. 69:699-704

6. Dann L, Fitzsimons J, Gorman KM, Hourihane J, Okafor I (2020) Disappearing act: COVID-19 and paediatric emergency department attendances. Arch Dis Child. 105:810-811

7. Chavasse R, Almario A, Christopher A, Kappos A, Shankar A (2020) The indirect impact of COVID-19 on children with asthma. Arch Bronconeumol:S0300-2896(20)30226-X

8. Wirrell EC, Grinspan ZM, Knupp KG, Jiang Y, Hammeed B, Mytinger JR et al (2020) Care delivery for children with epilepsy during the COVID-19 pandemic: an international survey of clinicians. J Child Neurol.:883073820940189

9. Angoulvant F, Ouldali N, Yang DD, Filser M, Gajdos V, Rybak A et al (2020) COVID-19 pandemic: Impact caused by school closure and national lockdown on pediatric visits and admissions for viral and non-viral infections, a time series analysis. Clin Infect Dis: ciaa710

10. Nolen LD, Seeman S, Bruden D, Klejka J, Desnoyers C, Tiesinga J et al (2020) Impact of social distancing and travel restrictions on non-COVID-19 respiratory hospital admissions in young children in rural Alaska. Clin Infect Dis:ciaa1328

11. Abdollahi E, Haworth-Brockman M, Keynan Y, Langley JM, Moghadas SM (2020) Simulating the effect of school closure during COVID-19 outbreaks in Ontario. Canada. BMC Med. 18:230

12. Iwata K, Doi A, Miyakoshi C (2020) Was school closure effective in mitigating coronavirus disease 2019 (COVID-19)? Time series analysis using Bayesian inference. Int J Infect Dis. 99:57-61

13. Auger KA, Shah SS, Richardson T, Hartley D, Hall M, Warniment A et al (2020) Association between statewide school closure and COVID-19 incidence and mortality in the US. JAMA. 324:859870

14. Watanabe T, Yabu T (2020) Japan's voluntary lockdown. Covid Economics. 46:1-31

15. Hamada H, Sekimoto M, Imanaka Y (2012) Effects of the per diem prospective payment system with DRG-like grouping system (DPC/PDPS) on resource usage and healthcare quality in Japan. Health Policy 107:194-201

16. Ministry of Health, Labour and Welfare. [Reports of a survey, "Discharged Patients Survey," for assessing the effects of introducing DPC, 2018.] 2020 Mar 25. https://www.mhlw.go.jp/stf/shingi2/ 0000196043 00003.html. Japanese. Accessed 20 September 2020

17. Bernal JL, Cummins S, Gasparrini A (2017) Interrupted time series regression for the evaluation of public health interventions: a tutorial. International Journal of Epidemiology. 46:348-355

18. Czeisler ME, Marynak K, Clarke KEN, Salah Z, Shakya I, Thierry JM et al (2020) Delay or avoidance of medical care because of COVID-19-related concerns - United States, June 2020. MMWR Morb Mortal Wkly Rep. 69:1250-1257

19. McDonnell T, Nicholson E, Conlon C, Barrett M, Cummins F, Hensey C et al (2020) Assessing the impact of COVID-19 public health stages on paediatric emergency attendance. Int J Environ Res Public Health. 17:E6719

20. Lau JTF, Griffiths S, Choi KC, Tsui HY (2010) Avoidance behaviors and negative psychological responses in the general population in the initial stage of the H1N1 pandemic in Hong Kong. BMC Infect Dis. 10:139

21. Jang WM, Cho S, Jang DH, Kim UN, Jung H, Lee JY et al (2019) Preventive behavioral responses to the 2015 Middle East respiratory syndrome coronavirus outbreak in Korea. Int $\mathrm{J}$ Environ Res Public Health. 16:2161

22. Simonsen L, Taylor RJ, Schuck-Paim C, Lustig R, Haber M, Klugman KP (2014) Effect of 13-valent pneumococcal conjugate vaccine on admissions to hospital 2 years after its introduction in the USA: a time series analysis. Lancet Respir Med. 2:387-394

23. Ouldali N, Bellettre X, Milcent K, Guedj R, de Pontual L, Cojocaru $B$ et al (2017) Impact of implementing national guidelines on antibiotic prescriptions for acute respiratory tract infections in pediatric emergency departments: an interrupted time series analysis. Clin Infect Dis. 65:1469-1476

24. Jackson C, Vynnycky E, Hawker J, Olowokure B, Mangtani P (2013) School closures and influenza: systematic review of epidemiological studies. BMJ Open 3:e002149

25. Jackson C, Mangtani P, Hawker J, Olowokure B, Vynnycky E (2014) The effects of school closures on influenza outbreaks and pandemics: systematic review of simulation studies. PLoS ONE 9(5):e97297

26. Bartsch SM, Ferguson MC, McKinnell JA, O'Shea KJ, Wedlock PT, Siegmund SS et al (2020) The potential health care costs and resource use associated with COVID-19 in the United States. Health Aff (Millwood) 39:927-935

27. Lee CCM, Thampi S, Lewin B, Lim TJD, Rippin B, Wong WH et al (2020) Battling COVID-19: critical care and peri-operative healthcare resource management strategies in a tertiary academic medical centre in Singapore. Anaesthesia. 75:861-871

28. Sadique MZ, Adams EJ, Edmunds WJ (2008) Estimating the costs of school closure for mitigating an influenza pandemic. BMC Public Health 8:135

29. Viner RM, Russell SJ, Croker H, Packer J, Ward J, Stansfield C et al (2020) School closure and management practices during coronavirus outbreaks including COVID-19: a rapid systematic review. Lancet Child Adolesc Health. 4:397-404

30. Petretto DR, Masala I, Masala C (2020) School closure and children in the outbreak of COVID-19. Clin Pract Epidemiol Ment Health. 16:189-191

Publisher's note Springer Nature remains neutral with regard to jurisdictional claims in published maps and institutional affiliations. 